\section{Spaced-trial partial reward in the lizard}

\author{
C. L. GRAF*
}

California State College at Los Angeles, Los Angeles, Calif. 90032

Two matched groups of lizards were given one trial a day for 90 days in a simple runway with partial and with consistent reward. During acquisition, running time of the partial reward group was slower than that of the consistent reward group. The groups showed no difference in resistance to extinction. The results were compared with similar spaced-trial runway studies using other organisms.

In massed-trial runway or simple strike situations, the partial reinforcement effect (PRE) has been demonstrated in rats, fish, and turtles (Bitterman \& Schoel, 1970), but in spaced trials with a 24-h intertrial interval (ITI), the PRE appeared only in rats and then only with large reward (Hulse, 1958; Wagner, 1961; Gonzalez \& Bitterman, 1969). Fish (Longo \& Bitterman, 1960; Schutz \& Bitterman, 1969 ) and turtles (Eskin \& Bitterman, 1961; Gonzalez \& Bitterman, 1962; Pert \& Bitterman, 1970) have consistently failed to show the spaced-trial PRE regardless of the magnitude of reward.

The present study was designed to determine the effect of spaced-trial, partial, and consistent reward in a reptile other than the turtle. The lizard previously showed a PRE of borderline statistical significance with a 20-min ITI (Richardson \& Graf, 1970). The present study is the first investigation of the PRE with 24-h ITI in lizards.

SUBJECTS AND APPARATUS

The Ss were 12 desert iguana (Dipsosaurus dorsalis) collected at Palm Springs, Calif. Their mean weight was $38 \mathrm{~g}$, and the mean snout vent length was $109 \mathrm{~mm}$. The animals were housed in wire mesh cages with sand and rocks on the floor. Meal worms and lettuce were fed daily, and water was available at all times. Heat was provided for $12 \mathrm{~h}$ a day by $250-\mathrm{W}$ infrared overhead lamps which sustained a floor temperature of $30^{\circ} \mathrm{C}$.

The apparatus was an L-shaped runway constructed of 1/4-in. plywood. A wire screen ladder, $12 \mathrm{~cm}$ long at a $45-\mathrm{deg}$ incline, led to the $15-\mathrm{cm}$ startbox, the $122-\mathrm{cm}$ alley, and the $15-\mathrm{cm}$ goalbox. The runway was $12 \mathrm{~cm}$ wide, with $12-\mathrm{cm}$ walls throughout. Removable wire screen doors separated adjacent sections so that the animals could not retrace from any section of the runway. The floor was covered with a fine-grade sandpaper, and a Plexiglas top over the

* The author is indebted to Professors Ann Richardson and John Haralson for their advice. runway allowed viewing by the $\mathrm{E}$. The entire apparatus was painted a flat gray. Illumination was provided by two $100-W$ bulbs suspended $152 \mathrm{~cm}$ over the runway. Latency and running time measures were obtained manually by the $E$ with two standard stopwatches.

\section{PROCEDURE}

Reward consisted of a 3-min exposure on a hot plate maintained at $38^{\circ} \mathrm{C}$. Such reward has been shown to be effective for these reptiles (Julian \& \& Richardson, 1968), who demonstrated no apparent satiation effects after repeated exposures. The 3-min exposure at $38^{\circ} \mathrm{C}$ resulted in an average increase of cloacal temperature from $33.3^{\circ}$ to $38.6^{\circ} \mathrm{C}$. Nonreward consisted of a 3 -min confinement on a hot plate maintained at $30^{\circ} \mathrm{C}$. At this temperature, the nonrewarded goal was the same temperature as that of the holding cage in which Ss were placed before and after each trial. The Ss showed no distress when in the holding cage, and thus at $30^{\circ} \mathrm{C}$, the nonrewarded goal was not an aversive stimulus.

The lizards were handled $10 \mathrm{~min}$ daily for 1 week prior to the start of the experiment. Acquisition trials were divided into two phases: in Phase 1, all Ss were given 12 trials, one trial a day, 6 days a week, on a consistent reward Richardson, 1968; Krekorian, Vance, extinction. schedule. On the basis of running time during these 12 trials, the $\mathrm{Ss}$ were divided into two matched groups, six is in each, and designated as Group PR and Group CR.

In Phase 2, the lizards received 42 trials, one trial a day, 6 days a week. The order in which experimental groups were tested alternated daily, and the Ss were chosen randomly within a group for the daily trials. Group PR received 21 rewarded and 21 nonrewarded trials in an abba sequence. If any $S$ remained in the startbox for $3 \mathrm{~min}$, the animal was removed to the holding cage and $3 \mathrm{~min}$ was recorded both for latency and running time. Once in the alley, a $S$ was allowed $3 \mathrm{~min}$ to reach the goal before it was removed and $3 \mathrm{~min}$ was recorded for running time. When in either the startbox or alley, a $\mathrm{S}$ was lightly prodded after remaining stationary for $1 \mathrm{~min}$ with eyes closed.

Extinction consisted of 36 trials, one trial a day, 6 days a week. The procedure was the same as that used on nonrewarded acquisition trials, except that Ss were never prodded. Both Groups PR and CR were detained $3 \mathrm{~min}$ on the nonrewarded goal. The study was terminated when running time and latency curves became relatively stable.

\section{RESULTS AND DISCUSSION}

Latency and running time scores showed similar acquisition and extinction curves; therefore, only running time is presented here. Figure 1 shows mean log running time in blocks of three trials. In Phase 1 of acquisition (Blocks 3-12), running time declined for all Ss in a negatively accelerated fashion typical of consistent reward. With the introduction of nonreward in Phase 2 of acquisition (Blocks 12-54), the mean running time of Group PR exceeded that of Group CR. An analysis of variance based on Phase 2 daily running time yields a significant

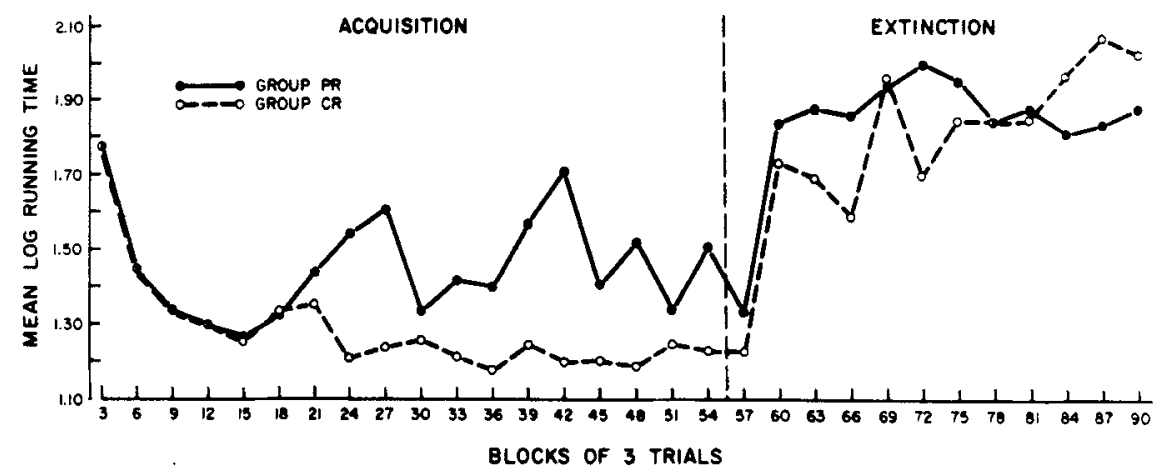

Fig. 1. Mean log running time in blocks of three trials for acquisition and 
groups effect, with Group PR running more slowly $(\mathrm{F}=49.6$. $\mathrm{dt}=1.200$. $p<.01)$, but a days effect $(F=1.0 \%$ $\mathrm{df}=41 / 420, \mathrm{p}>.05)$ and an interaction $(F=1.26$, df $=41+20$. $\mathrm{p}>.05$ ), each short of significance. Slower running in $P R$ Ss was also reported in turtles by Gonzalez \& Bitterman (1962). On the other hand. Eskin \& Bitterman (1961) and Pert \& Bitterman (1970) found similar running in $P R$ and $C R$ turtles. This discrepancy may be a function of the long duration of nonreward used in the present study and in the study by Gonzalez \& Bitterman (1962). since 3 -min and 1-min confinements were employed in contrast with Gonzalez \& Bitterman (1961) and Pert \& Bitterman (1970), where the typical short duration of nonreward (20- and $30-\mathrm{sec}$ confinements) was used. The latter procedure failed to produce slower running in PR turtles.

A second feature of the present acquisition results was the occurrence in Group PR of faster running on trials following reward and slower running on trials following nonreward. Using the $t$ test, the mean difference between running time on rewarded trials and trials following reward was significant at $\mathrm{p}<.01$; the same significant difference was found between running time on nonrewarded trials and trials following nonreward (p -.01$)$. This finding indicates that trial effects (reward and nonreward) can remain functional in lizards for at least a 24 -h interval.

Throughout extinction (Fig. 1), there was no reliable difference between the running time of Group PR and that of Group CR. An analysis of variance based on extinction daily running time yields a negligible groups effect $(\mathrm{F}=0.50, \mathrm{df}=$ $1 / 360, \quad p>.05)$, a significant days effect $(F=1.89, \mathrm{df}=35 / 360$, $p<.01)$, and an interaction short of significance $(\mathrm{F}=1.15, \mathrm{df}=35 / 360$, $\mathrm{p}>.05)$. These results indicate that extinction occurred similarly in Groups PR and CR. Thus, the spaced-trial PRE found in rats failed to appear in lizards. This finding confirms the results of previous studies with turtles and lends support to the hypothesis that reptiles fail to show the spaced-trial PRE.

\section{REFERENCES}

BITTERMAN, M. E., \& SCHOEL, W, M. Instrumental learning in animals: Parameters of reinforcement. Annual Review of Psychology, 1970, 21, 367-435.

ESKIN, R. M., \& BITTERMAN, M. E. Partial reinforcement in the turtle. Quarterly Journal of Experimental Psychology, 1961, 13,112-116.

GONZALEZ, R. C., \& BITTERMAN, M. E. $A$ further study of partial reinforcement in the turtle. Quarterly Journal of Experimental Psychology, 1962, 14. 109-112.

GONZALEZ, R. C., \& BITTERMAN. M. E. Spaced-trials partial reinforcement effect as a function of contrast. Journal of Comparative \& Physiological Psychology, $1969,67,94-103$.

HULSE, S. H., JR. Amount and percentage of reinforcement and duration of goal confinement in conditioning and extinction. Journal of Experimental Psychology, 1958,56, 48-57.

JULIAN, B. E.. \& RICHARDSON. A. M. Maze learning in the lizard Dipsosaurus dorsalis. Journal of Biological Psychology, 1968, X, 4-9.

KREKORIAN, C. O., VANCE, V. J. \& R I C H A R D S O N N A . M. Temperature-dependent maze learning in the desert iguana, Dipsosaurus dorsalis. Animal Behaviour, 1968, 16, 429-436.

LONGO, N.. \& BITTERMAN, M. E. The effect of partial reinforcement with spaced practice on resistance to extinetion in the fish. Journal of Comparative \& Physiological Psychology, $1960,53,169-172$.

PERT, A. \& BITTERMAN, M. E. Reward and learning in the turtle. Learning \& Motivation, $1970,1,121-128$.

RICHARDSON, A. M., \& GRAF, C. L. Partial reinforcement effects in the lizard, Dipsosaurus dorsalis. Paper presented at the meeting of the Western Psychological Association, Los Angeles. A pril 1970

SCHUTZ, S. L., \& BITTERMAN, M. E. Spaced-trials partial reinforcement and resistance to extinction in the goldfish. Journal of Comparative \& Physiological Psychology, 1969, 68, 126-128.

WAGNER, A. R. Effects of amount and percentage of reinforcement and number of acquisition trials on conditioning and extinction. Journal of Experimental Psychology, 1961,62, 234-242. 